\title{
UM MUNDO DENTRO DO MUNDO: UM ESTUDO DE FINISTERRA, DE CARLOS DE OLIVEIRA
}

\author{
Isabelita Maria Crosariol \\ Doutoranda em Estudos da Literatura pela PUC-Rio
}

\section{RESUMO}

$\mathrm{O}$ artigo tem o propósito de analisar o romance Finisterra, do escritor português Carlos de Oliveira, a partir de critérios formais. Em função disso, em vez de uma leitura interessada em focalizar tão somente o conteúdo da obra, o que se sugere ao longo do texto é uma abordagem que, sem desconsiderar o contexto, evidencie que as obras neorealistas não são meros pretextos para a exposição de um discurso marxista, mas sim produções resultantes de um trabalho cuidadoso com as palavras.

PALAVRAS-CHAVE

Literatura; Referencialidade; Carlos de Oliveira.

\section{A WORLD INSIDE THE WORLD: A STUDY OF FINISTERRA, BY CARLOS DE OLIVEIRA}

\begin{abstract}
The essay has the purpose of analyzing the novel Finisterra, by the Portuguese writer Carlos de Oliveira, using formal criteria. Due to this, instead of a reading interested in just paying attention to the content of the work, it suggests an approach that, without disregarding the context, evidences that the neo-realist works are not mere pretext to the exposition of a Marxist discourse, but productions resultant of a careful work with the words.
\end{abstract}

\section{KEYWORDS}

Literature; Referentiality; Carlos de Oliveira. 
A luz de carbureto

que ferve no gasômetro do pátio

e envolve este soneto

num cheiro de laranjas com sulfato

(as asas pantanosas dos insectos

reflectidas nos olhos, no olfacto,

a febre a consumir o meu retrato,

a ameaçar os tectos

da casa que também adoecia

ao contágio da lama

e enfim morria

nos alicerces como numa cama)

a pedregosa luz da poesia

que reconstrói a casa, chama a chama.

Carlos de Oliveira

A progressiva destruição de uma casa (simbolicamente tomada por Carlos de Oliveira como um microcosmo de Portugal) e a tentativa de captá-la por meio da arte é o tema do poema acima transcrito, publicado em 1968 sob o título de "Casa" na obra Sobre o lado esquerdo. Contudo, é este também o tema de Finisterra, romance publicado dez anos depois, e no qual a exposição da "decadência de uma família (e de uma classe social) através da progressiva ruína de uma casa” (MARTELO, 2000, p. 251), por sua vez, deixa entrever uma clara aproximação da obra com o primeiro romance do autor: Casa na duna, de 1943.

Essas aproximações, no entanto, não são casuais. Inserem-se em uma proposta de "escrita em movimento", expressão que remete ao fato de, a cada nova edição lançada, os livros de Carlos de Oliveira serem revistos e alterados pelo autor que, entretido em sua "alquimia dos papéis velhos" (OLIVEIRA, 1971, p. 203), buscava conferir à sua obra uma maior contensão. Ao longo desse processo, portanto, aquilo de que se fala é sempre o mesmo. Muda a linguagem, o modo de reconstruir o mundo. E parece-nos que é justamente essa questão que é trazida à tona em Finisterra tanto no plano da forma como no do conteúdo. No plano da forma, visto que a exposição da destruição de uma casa em meio às dunas na região da Gândara é feita novamente pelo autor, porém com uma nova roupagem; já no plano do conteúdo, porque, ao mostrar os diferentes modos como uma paisagem vista da janela pode ser apreendida e representada por vários personagens da narrativa (por meio do desenho, fotografia, pirogravura, maquete, entre outros), introduz-se uma discussão a respeito da articulação entre a arte e o mundo.

Antoine Compagnon, ao se deter, em capítulo intitulado "O mundo", especificamente no estudo das possíveis relações que a literatura estabelece com o 
mundo, afirma que "a mimésis, desde a Poética de Aristóteles, é o termo mais geral e corrente sobre o qual se conceberam as relações entre a literatura e a realidade" (1999, p. 97). Tomado em diferentes acepções, o termo aristotélico ora foi empregado para sustentar a posição da literatura como cópia, como uma pintura da realidade (tal como queria Eça ${ }^{1}$ ), ora para embasar um pensamento segundo o qual a literatura desfrutava de uma autonomia em relação à realidade. Difundido pela teoria literária, este último ponto de vista forçou o rompimento dos elos entre a literatura e o mundo, ao salientar que " $O$ mundo é sempre já interpretado, pois a relação linguística primária ocorreu entre as representações, não entre a palavra e a coisa, nem entre o texto e o mundo. Na cadeia sem fim nem origem das representações, o mito da referência se evapora" (COMPAGNON, 1999, p. 99). Assim, a literatura falaria apenas da literatura, visto que não haveria relação efetiva entre a literatura e a realidade.

Todavia, para Compagnon, faz-se necessário sair desse binarismo - ou a literatura fala do mundo, ou a literatura fala da literatura -, pois ambas as posições são insustentáveis. A literatura não imita o mundo, tampouco é ausente de uma exterioridade. "A mimésis é [...] conhecimento, e não cópia ou réplica idênticas: designa um conhecimento próprio ao homem, a maneira pela qual ele constrói, habita o mundo" (COMPAGNON, 1999, p. 127). Remete, portanto, não apenas ao modo como um artista compõe determinada paisagem, mas também à forma como executa o seu povoamento.

Ao longo desse processo,

[...] na ficção se realizam os mesmos atos de linguagem que no mundo real: perguntas e promessas são feitas, ordens são dadas. [...] A literatura explora as propriedades referenciais da linguagem; seus atos de linguagem são fíctícios, mas, uma vez que entramos na literatura, que nos instalamos nela, o funcionamento dos atos de linguagem fictícios é exatamente o mesmo que o dos atos de linguagem reais, fora da literatura. (COMPAGNON, 1999, p. 135).

Essa mesma problemática é levantada por Rosa Maria Martelo em obra intitulada Carlos de Oliveira e a referência em poesia, no momento em que a pesquisadora expõe que, se para a tradição realista do século XIX, a referencialidade da

\footnotetext{
${ }^{1}$ Se nas Conferências do Cassino, Eça já anunciava o seu propósito de pintar a sociedade portuguesa quando afirmava que "O Romantismo era a apoteose do sentimento; o Realismo é a anatomia do caráter. É a crítica do homem. É a arte que nos pinta a nossos olhos - para condenar o que houver de mal na sociedade" (apud ABDALA JUNIOR, 2007, p. 212), em carta escrita a Teófilo Braga em 1978, o escritor reafirma essa intenção quando escreve: "A minha ambição seria pintar a sociedade portuguesa tal qual fez o constitucionalismo desde 1830 e mostrar-lhe, como num espelho, que triste país eles formam - eles e elas.” (apud ABDALA JUNIOR, 2007, p. 212, grifo nosso).
} 
obra realista se distinguia "precisamente pelo fato de esse tipo de obras denotarem alguma coisa, no sentido em que uma fotografia - alguma fotografia - remete para um objeto cuja existência prévia simultaneamente comprova" (1998, p. 33), para as teorias de não-referência poética do início do século XX, por sua vez, essa articulação proposta pelo Realismo aparecia de modo invertido. Para a concepção estruturalista, por exemplo, era bastante claro que, "se a literatura faz um uso conotativo da linguagem não pode denotar e, conseqüentemente, não é referencial: a sua referencialidade reduz-se, então a uma aporia, a um 'desejo do impossível'” (1998, p. 33), termo originalmente empregado por Barthes.

A partir desses dois modos de conceber as relações entre literatura e mundo, Martelo então propõe uma nova abordagem que pressuponha tanto

[...] a superação da identificação da referencialidade com a representação de um mundo independente das linguagens pelas quais se constitui, como da noção autotélica do texto poético para a qual as poéticas simbolista e modernista e o adensamento da reflexividade na literatura do século XX contribuíram de forma decisiva. (1998, p. 334)

Isto significa que, em vez de se conceber o texto como cópia do mundo, ou como produto a ele alheio, deve-se encará-lo a partir de uma posição intermediária, fugindo do binarismo ou um, ou outro. Deve-se partir de uma concepção de literatura que não seja espelho (como reivindicou Eça no final do século XIX), mas que também não ignore os vínculos da arte com a realidade.

No prefácio da terceira edição de Casa na Duna, Mário Dionísio afirma haver dois tipos de artistas: "os que vivem e trabalham de fora para dentro e os que vivem e trabalham de dentro para fora. [...] Os primeiros, sobretudo, contam histórias com toda a variedade e sedução do seu talento pessoal; os segundos, sobretudo, contam-se através das histórias que nos contam" (1964, p. 17, grifo do autor). Entre eles está Carlos de Oliveira, escritor para o qual:

[...] não se trata nunca de coser uma história, mas servir-se duma história para criar uma nova realidade estética, de transformar o que desprevenidamente viu, sentiu, viveu (de transformar-se) nesse tal mundo dentro do mundo, que do mundo vem, para o mundo volta e nele permanece, alargando-o, enriquecendo-o, através dessa operação prodigiosa em que as palavras, sem deixarem de ser um meio - o meio por excelência - são também um fim. Escritor de dentro para fora, Carlos de Oliveira tem um só tema: ele próprio que se define pela 
identificação interior e espontânea com o sofrimento do homem. (DIONÍSIO, 1964, p. 19-20)

Neste sentido, as relações que a criação de Carlos de Oliveira estabelece com o mundo não são de cópia. O que o artista busca é a produção de um efeito de "mais de realidade" (DELEUZE, 2005, p. 9) a partir de situações comuns, por meio "duma orientação narrativa no sentido do concreto, do imediatismo visual, do caráter global das ações, do gesto, do objeto, do pormenor, mas só do pormenor que conta em relação ao texto todo" (DIONÍSIO, 1964, p. 41). Assim, o olhar do leitor, ao se aproximar de elementos e de situações aparentemente insignificantes, pode ser despertado pela revelação da nudez, da crueza e da brutalidade que também envolvem a banalidade cotidiana (DELEUZE, 2005). É a “arte do encontro", para usar um termo do cineasta italiano Cesare Zavattini (apud DELEUZE, 2005, p. 10).

Nascido no Brasil, ainda criança Carlos de Oliveira foi levado por seus pais a Portugal. Lá morou em uma região que marcaria profundamente a sua criação: a Gândara, lugar esquecido em meios aos pinhais, onde "vivem homens semeando e colhendo, quando o estio poupa as espigas e o inverno não desaba em chuva e lama. Porque então são ramagens torcidas, barrancos, solidão naquelas terras pobres" (OLIVEIRA, 1970, p. 7). Foi a vivência nesse fim do mundo (ou seria melhor finisterra?) que ofereceu a Carlos de Oliveira, elementos que lhe possibilitaram criar outros mundos por meio da arte. Arte, portanto, enquanto criação de um "mundo dentro do mundo", como acertadamente definiu Mário Dionísio.

Estando em consonância com a poética neo-realista, novos mundos são construídos nas obras de Carlos de Oliveira a partir de "uma intenção manifesta de referencialidade" (MARTELO, 1998, p. 31), o que implica a consciência, por parte do escritor, da função heurística de seus textos. "Tal significa que a referencialidade não implicará tanto o reconhecimento de um mundo por parte do leitor, quanto o seu reconhecimento" (MARTELO, 1998, p. 33, grifo do autor). Em Finisterra, por exemplo, o mundo criado por meio da condensação de idéias em palavras pressupõe a participação do leitor justamente no desvendamento dos silêncios deixados pela narrativa. Como nos explica Carlos de Oliveira, ao analisar sua obra Micropaisagem (e nesse ponto partimos da premissa de que a afirmação do autor se estende a toda a sua produção): 
Todo esse rigor, toda essa frieza, partiram assim do real, do quotidiano. Frieza aparente, julgo eu. O livro, qualquer livro é uma proposta feita à sensibilidade, à inteligência do leitor: são elas que em última análise o escrevem. Quanto mais depurada for a proposta (dentro de certos limites, claro está), maior a sua margem de silêncio, maior a sua inesperada carga explosiva. A proposta, a pequena bomba de relógio, é entregue ao leitor. Se a explosão se der ouve-se melhor no silêncio. (1971, p. 205)

Os elementos do cotidiano, portanto, ao serem incorporados à ficção, submetem-se à remodelagem ditada por uma proposta de silêncio, de brevidade e de explosão. Desvinculados do compromisso de serem espelhos, revelam sua ampla capacidade de assumirem formas múltiplas e diversas, dependendo do olhar interpretativo daquele que os reproduz. $\mathrm{O}$ ato de olhar uma imagem a partir de uma janela e de tentar reproduzi-la ilustra bem a afirmação que aqui se faz. Ainda que a paisagem seja a mesma, a imagem apreendida por vários indivíduos nunca será igual, tampouco a sua reprodução, uma vez que, "nas relações sujeito-objeto, o sujeito faz parte da realidade e sem ele (que sente as coisas) nada teria sentido" (OLIVEIRA, 1979, p. 31).

Sentado em um osso de baleia, com um caderno apoiado nos joelhos, um menino olha a paisagem da Gândara e começa a desenhá-la, "sem se empenhar numa cópia excessiva" (OLIVEIRA, 1979, p. 9). Surpreendido pela chuva, entra em sua casa, e continua o desenho. Agora a paisagem lhe aparece emoldurada pela janela, e é guiando-se pela memória que ele busca reproduzir aquilo que anteriormente viu. É sob essas circunstâncias que a criança, logo no início do romance Finisterra, cria, em seu caderno, "os seres primordiais, mistura verão e inverno, atenua a cegueira (o excesso) do sol incidindo sobre sílica, mica esmigalhada, vidro moído num almofariz (sabe-se lá), aumenta os grãos de areia até ao tamanho que parecem ter, de noite, quando o vento atira contra as vidraças a sua enorme pedrada" (OLIVEIRA, 1979, p. 4).

Quando questionada pelo adulto a respeito de seu desenho, a criança explica que as chamas que saem dos vultos negros com que povoa a paisagem eram provavelmente uma conseqüência da febre que ela todas as tardes apresentava. Já a escassez de água justificava-se pela sede que então sentia - "Quando temos sede, a água parece sempre pouca" (OLIVEIRA, 1979, p. 12) -, enquanto que os grãos de areia, embora parecessem enormes, eram menores do que aqueles que batiam contra a janela no inverno. A imagem criada pela criança em seu desenho revela-se, pois, assumidamente, como produto de um sujeito, que não apenas filtra a paisagem (e dela 
separa aquilo que lhe interessa), como também modifica aquilo que vê, exagerando determinados detalhes, produzindo deformações, e acrescentando informações.

Ainda em um momento posterior à elaboração de seu desenho, a criança examinará novamente a imagem que irrompe pela janela, tal como alguém que se detém diante de um quadro em busca de seu entendimento. E, a partir desse ato, chegará à seguinte reflexão:

A primeira zona de areia (mancha a ferver num hálito prateado, como o sal dos velhos itinerários: ruivo por dentro, alvo por fora) ocupa o terço inferior da aridez que a janela enquadra.

Segue-se uma faixa estreita de gramínea: a evaporação da lagoa (juncos densamente roxos) submerge-as num tom mais carregado que o da própria água. Esta área, no entanto, é bastante instável: sob a declinação do sol, as cores mudam com freqüência de intensidade; basta um sopro de vento, a ondulação pouco perceptível que provoca, para clarear ou escurecer as gramíneas.

$\mathrm{Na}$ outra margem, a linha das dunas reflecte o movimento dessa ondulação (sinusóide tênue demarcando a altura da segunda grande zona de areia) e serve de limite ao terço intermédio da paisagem.

O último terço acaba na linha superior do caixilho: formam-no as dunas distantes (recorte acentuado, revérberos de cal, como a auréola, a inquietação, que as estrelas irradiam fixamente). Ao fundo, uma nesga de azul pode parecer ao mesmo tempo céu e mar; placa de zinco a incendiar-se; ou apenas um reflexo turvo da luz. (1979, p. 7-8).

A aproximação da paisagem vista pela janela com um quadro transforma, neste contexto, o desenho da criança em uma representação criada a partir de uma representação anterior. Trata-se de um processo semelhante àquele desenvolvido por Carlos de Oliveira em seu poema "Descrição da guerra em Guernica". No texto em questão, o célebre quadro de Picasso serve de mote para que o poeta não apenas recupere o contexto de morte e de destruição veiculado pela obra do pintor espanhol, como também o associe ao contexto vivenciado por Portugal durante o fascismo português. Assim, aquilo que a criança faz, seja em seu desenho produzido a partir do recorte da paisagem, seja na enunciação de sua reflexão sobre o conteúdo emoldurado na janela, é expor, por meio de uma outra linguagem, um conteúdo preexistente, modificando-o, contudo, segundo determinadas motivações.

Cabe aqui lembrar que a pequena lagoa e o grão de areia enorme desenhados pela criança trazem à tona a preocupação das populações da Gândara de se viver na terra improdutiva e arenosa que os peregrinos escolheram para povoar, mas que hoje se corre o risco de perder. "Vês? A sede sempre existe: minha ou deles, tanto faz. Aqui, 
encenação e real coincidem" (OLIVEIRA, 1979, p. 23). Captar a imagem dessa terra por meio do desenho é, pois, um modo de assegurar sua posse, de conservá-la intocada, alheia às influências da luz ou às mudanças da paisagem provocadas pelo vento.

Em ensaio intitulado "Para além da imagem-movimento", Gilles Deleuze (2005), partindo da necessidade de se estabelecer critérios formais e estéticos para a chamada arte neo-realista, explica que nessas obras verifica-se a passagem de um esquema sensório motor simples para uma situação ótica pura, o que implica não mais a identificação do leitor/espectador com aquilo que tem diante de si, mas a inclusão da figura do observador na obra. Desse modo,

[...] por mais que [ele] se mexa, corra, agite, a situação em que está extravasa, de todos os lados, suas capacidades motoras, e lhe faz ver e ouvir o que não é mais passível, em princípio, de uma resposta ou ação. Ele registra, mais que reage. Está entregue a uma visão, perseguido por ela ou perseguindo-a, mais que engajado numa ação. (DELEUZE, 2005, p. 11)

Ainda segundo Deleuze, nesse contexto de representação da impossibilidade de agir perante uma situação, a criança possui uma grande importância. Afinal, "no mundo adulto, a criança é afetada por uma certa impotência motora, mas que aumenta sua aptidão a ver e ouvir” (2005, p. 12). Impotência que, nas palavras de Carlos de Oliveira, seria a responsável por revelar um sentimento de solidariedade com "a pobreza, a nudez, a carência de quase tudo" (1971, p. 207).

E qual a diferença entre o desenho da criança, a imagem da paisagem emoldurada pela janela e uma fotografia? É esta mesma a indagação que povoa os pensamentos da criança precoce. Sua conclusão é semelhante àquela teorizada em certo ponto do romance: a foto não constitui uma cópia do real - "A imagem não é perfeita (escapam-lhe alguns pormenores), mas foi o ponto de partida" (OLIVEIRA, 1979, p. 28). Sob o efeito do tempo, sua imagem fora reduzida praticamente a uma mancha em tom sépia, e os contornos das figuras não estão mais definidos. Logo, até mesmo a pretensão de congelar o real por meio de uma foto revela-se como prática incapaz de desafiar o poder destruidor do tempo.

O mesmo pode ser dito a respeito dos poucos e dispersos papéis da família, cuja legibilidade foi comprometida pelo passar dos anos. Neles também se verifica, por meio do discurso do pioneiro, a consciência da instabilidade do local que se escolheu para povoar: "o litoral instável sob os nossos pés; as dunas prontas a mover-se; basta um 
golpe de vento" (OLIVEIRA, 1979, p. 20). Desse modo, tal como a casa construída por Silvério Coxo, em Casa na Duna, a casa que aparece em Finisterra já dava indícios desde o tempo dos peregrinos que um dia iria desmoronar.

A seguir, ao se aproximar de uma almofada de carneiro pirogravada, a criança se detém diante de uma nova forma de se recriar a imagem vista da janela, e constata que:

Lavrado a fogo, o sulco do estilete nunca se interrompe, tece a teia castanho-escura no castanho mais aberto do material, sugere uma gravura abstrata, repete com rigor o traço das dunas, as margens da lagoa, a rede confusa das gramíneas, equilibrando geometricamente superfícies, volumes, relações de espaço: a arquitetura real (?) da paisagem. (OLIVEIRA, 1979, p. 9)

Como uma gravura abstrata pode ser capaz de repetir com rigor o traço das dunas, sendo que a abstração preza justamente pela não-representação de objetos de uma realidade exterior? Significaria isto que o alheamento das coisas do mundo, embora desejado por uma concepção abstrata da arte, é algo impossível? E o que é a arquitetura real de uma paisagem? É possível apreendê-la artisticamente? Parece-nos que esses questionamentos evocados na observação da pirogravura poderiam ser condensados em uma única pergunta: “Quod est veritas?” (OLIVEIRA, 1979, p. 11).

$\mathrm{Na}$ opinião da mãe da criança, é justamente por partir da magia e da imaginação que a arte revela o compromisso de um sujeito em "colher o rigor submerso da realidade" (OLIVEIRA, 1979, p. 29), o que significa que, sem se desprender da paisagem, a imaginação traz à tona não apenas aquilo que se vê (e o que também não se vê), mas a própria presença desse sujeito, e o modo como ele interpreta o mundo:

Quer dizer, o pormenor sou eu. Somos nós, criaturas de Deus? Não posso admiti-lo. Ponho de parte temas acessórios: imperfeição da máquina, semelhança artificial com o nosso olhar. Tem a realidade o fascínio de um tesouro escondido? Creio bem que sim. E a entrega mecânica à tentação acaba por destruir-nos. $\mathrm{O}$ real não é diabólico em si mesmo. Longe disso. Mas podemos (oxalá não esteja a aproximarme da confusão) contaminá-lo sem saber.

Aponta a almofada de carneira:

- Uma gravura abstracta. Perto da geometria, da arquitetura submersa nas coisas. Mas foi a minha imaginação (partindo do real, eu sei) a construí-la. Magia para filtrar o mundo, dar-lhe algum sentido. (OLIVEIRA, 1979, p. 31, grifo nosso) 
A imagem pirogravada pela mãe da criança mostra-se então, na narrativa, assumidamente como uma imagem filtrada do real. Segundo esse ponto de vista, todo artista seria uma espécie de filtro que seleciona, a partir de uma matéria previamente dada, os elementos que lhe interessam. Desse modo, o produto final seria sempre um novo mundo criado a partir do mundo que efetivamente se vê.

Também no caso da mãe da criança, o desejo de representar a paisagem constitui uma obsessão, cujo ápice ocorre no instante em que, não satisfeita em desenhar sobre o couro retirado de algum carneiro, a mulher decide desenhar sobre um animal vivo, tendo a ajuda do amigo da família:

Pele espaçosa, para trabalhar à vontade. Dá uma bela paisagem.

Esta, não me agrada muito.

Nem a mim. Árvores, ramos e áleas: tudo rectilíneo. Prefiro a outra, que se vê da janela. As dunas, o deserto: linhas mais suaves.

E sabe-a de cor?

Passei a vida a olhá-la. Que lhe parece?

Alisa (prepara) a pele do cordeiro. Começa a pirogravar, excitada, mas os primeiros traços saem mal. Entusiasma-se, esquecendo o rasgão do fole, e o estilete arrefece. Os óculos escorregam pelo nariz, afastamse dos olhos. Pior ainda: vagas de arrepios ondeiam o cordeiro, e os traços (claro) ficam trêmulos, a paisagem cheia de rugas.

Tenha paciência, tente serená-lo. (OLIVEIRA, 1979, p. 160)

Nesse instante, um corte que o amigo da família tinha nos lábios se rompe. Jorra seu sangue e jorra também sangue do carneiro. A paisagem que a mulher desenhava na pele do animal se modifica: "Duas fontes vermelhas gotejam sobre a areia. Derretem os blocos de gelo, os dejectos do bicho assustado, misturam-se e turvam o azul da álea. Lama roxa, ameaçando a floresta (o equilíbrio das cores)" (OLIVEIRA, 1979, p. 161).

Mais uma vez fica evidente a impossibilidade de se reproduzir a paisagem tal como ela é, inclusive porque o olhar daquele que a observa pode se equivocar. É isso o que ocorre quando, ao ser advertida pelo tio, que estancara as duas fontes de sangue, a respeito do perigo de estragar a paisagem caso insistisse em seu desenho, a mulher decide apagar o estilete nos lagos verdes que desenhou. No entanto, a queda de seus óculos impede-a de discernir o que tem diante de si, e é assim que ela "mergulha (suavemente) o estilete em brasa no olho esquerdo do cordeiro" (OLIVEIRA, 1979, p. $163)$. 
Contudo, não são apenas a criança e a mãe que têm a atenção voltada para a contemplação da janela. A observação da paisagem constitui, em Finisterra, uma obsessão de toda a família. É como se, impedidas de agir, de evitar a ruína da casa onde vivem, todas as personagens apenas se dedicassem à observação do mundo exterior e à tentativa de reproduzi-lo. Ao longo desse processo,

[...] olhar e mãos se ligam: vê-se e se observa o que as mãos, de uma forma ou outra, fabricaram: a fotografia, a almofada, o desenho, a propriedade rural cuja riqueza as mãos mais ou menos anônimas também construíram. Na continuidade/complementaridade entre mãos e olhos põe-se com clareza o tema do trabalho ${ }^{2}$. Trabalharam mãos, com efeito, para dar existência a uma imagem (foto, pirogravura, desenho...) que circunscreva e represente, dominando-a, uma realidade fluida, fugidia. Sobre a imagem construída, laboriosamente fabricada, trabalhará depois o olhar. As mãos fornecem, assim, a matéria organizada (forma de riqueza?) que os olhos examinam. A atividade desses não existiria sem a prévia atividade daquelas. Mas, por outro lado - e isto é fundamental para se propor a imbricação olhos/mãos -, só se fabrica o já visto, discernido, circunscrito e, até, de certa forma dominado pelo olhar. (LEPECKI, 1988, p. 54, grifos do autor)

Como explica Deleuze, na concepção neo-realista da arte, as mãos se tornam uma extensão do olhar, pois têm "um papel que extravasa infinitamente as exigências sensório-motoras da ação, que até substitui o rosto, do ponto de vista das afecções, e que, do ponto de vista da percepção, torna-se o modo de construção de um espaço adequado às decisões do espírito" $(2005$, p. 22). Isto significa que, renunciando às suas funções preensíveis e motoras, as mãos, tal como o olhar, são responsáveis pela conexão de certos pedaços de espaços e pela reordenação da realidade que se tem diante de si.

Todavia, se em Finisterra, a articulação do olhar e do fazer constitui um modo de as personagens tentarem se libertar de uma catástrofe iminente por meio da criação de simulacros do mundo, o que se evidencia, no decorrer da narrativa, é o poder perturbador gerado por esses novos mundos. Sendo representações do real, os mundos recriados não são mais o mundo do qual inicialmente se partiu.

"É o fim do mundo" (OLIVEIRA, 19-?, p. 5), diria então o astrólogo amigo do poema "Estrelas".

Mas outro amigo, o inventor de jogos, diz-me:

"Deixe-o falar. Incline a cabeça para o lado, altere o ângulo de visão"

\footnotetext{
${ }^{2}$ Não surpreende aqui que a última antologia poética de Carlos de Oliveira seja justamente intitulada Trabalho poético, evidenciando a estreita relação entre o olhar do artista que capta o mundo, e as mãos que o reconfiguram por meio da arte.
} 
Sigo o conselho: e as estrelas rebentam num grande fulgor, os revérberos embatem nos caixilhos que lembram a moldura dum desenho infantil. (OLIVEIRA, 19-?, p. 5)

A magia da arte não está, portanto, na cópia fiel daquilo que se vê. Está nessa leve inclinação das cabeças para o lado, que permite a cada um conceber e recriar o mundo à sua maneira.

\section{REFERÊNCIAS}

ABDALA JUNIOR, Benjamin. Literaturas de Língua Portuguesa: Marcos e MarcasPortugal. São Paulo: Arte \& Ciência, 2007.

COMPAGNON, Antoine. "O mundo" in O demônio da teoria: Literatura e senso comum. Trad. Cleonice Paes Barreto Mourão. Belo Horizonte: Editora UFMG, 1999.

DELEUZE, Gilles. A imagem-tempo. Trad. Eloísa de Araújo Ribeiro. São Paulo: Brasiliense, 2005.

DIONİSIO, Mário. Prefácio in: OLIVEIRA, Carlos de. Casa na duna. 3. ed. Lisboa: Portugália, 1964.

LEPECKI, Maria Lúcia. "Carlos de Oliveira: Finisterra, a casa, as mãos, o tempo" in Sobreimpressões: Estudos de literatura portuguesa e africana. Lisboa: Editorial Caminho, 1988.

MARTELO, Rosa Maria. Carlos de Oliveira e a referência em poesia. Porto: Campo das Letras, 1998.

. "Casas destruídas: A revisitação de Casa na Duna em Finisterra de Carlos de

Oliveira” in Línguas e Literaturas. Porto, XVII, 2000, p. 251-260.

OLIVEIRA, Carlos de. Casa na Duna. 4. ed. Lisboa: Dom Quixote, 1970.

. Finisterra. Lisboa: Livraria Sá da Costa Editora, 1979.

. O aprendiz de feiticeiro. Lisboa: Dom Quixote, 1971.

. Trabalho poético. v. 2. Lisboa: Sá da Costa, [19-?]. 